\title{
Author Correction: Attribution of global lake systems change to anthropogenic forcing
}

Luke Grant (1), Inne Vanderkelen (1), Lukas Gudmundsson (1), Zeli Tan (D), Marjorie Perroud, Victor M. Stepanenko (D),

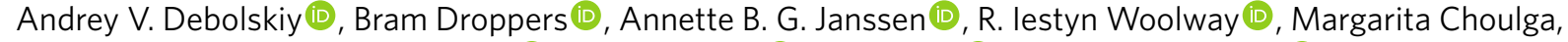

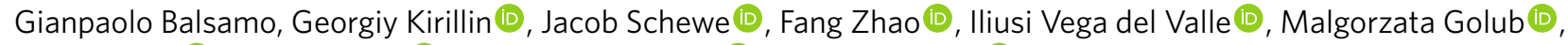
Don Pierson (1), Rafael Marcé (D), Sonia I. Seneviratne (D) and Wim Thiery $\mathbb{B}$

Correction to: Nature Geoscience https://doi.org/10.1038/s41561-021-00833-x, published online 18 October 2021.

In the version of this Article originally published, there was an error in the title of ref. 42. The citation has now been amended to read "42. Tan, Z. et al. Modeling methane emissions from arctic lakes: Model development and site-level study. J. Adv. Model. Earth Syst. 6, 513-526 (2015).”

The change has been made to the online version of the article.

Published online: 11 November 2021

https://doi.org/10.1038/s41561-021-00866-2

(C) The Author(s), under exclusive licence to Springer Nature Limited 2021 